\title{
A comparative study of internal laser-assisted and conventional liposuction: a look at the influence of drugs and major surgery on laboratory postoperative values
}

\author{
This article was published in the following Dove Press journal: \\ Drug Design, Development and Therapy \\ II October 2013 \\ Number of times this article has been viewed
}

\author{
Andrzej Feliks Przylipiak' \\ Elżbieta Galicka' \\ Magdalena Donejko' \\ Marek Niczyporuk' \\ Jerzy Przylipiak²
}

'Department of Aesthetic Medicine, Faculty of Pharmacy, Medical

University of Białystok, Białystok, Poland; ${ }^{2}$ Medical Office, Białystok, Poland
Correspondence: Andrzej Feliks Przylipiak

Department of Aesthetic Medicine, Faculty of Pharmacy, Medical University of Białystok, 15-267 Białystok, Poland Tel +48 857485822

Email medycynaestetyczna@umb.edu.pl
Background: Liposuction is a type of aesthetic surgery that has been performed on humans for decades. There is not much literature addressing the subject matter of pre- and post-surgery blood parameters, although this information is rather interesting. Documentation on patients who received laser-assisted liposuction treatment is particularly scarce. Until now, there has been no literature showing values of platelets, lymphocytes, and neutrophils after liposuction.

Purpose: The aim of the work is to analyze and interpret values of platelets, lymphocytes and neutrophils in patient blood before and after liposuction, a surgery in which an extraordinarily large amount of potent drugs are used. Moreover, the aim is to compare values changes in patients of conventional and laser-assisted liposuction.

Material and methods: We evaluated standard blood samples in patients prior to and after liposuction. This paper covers the number of platelets, lymphocytes, and neutrophils. A total of 54 patients were examined. Moreover, we compared the change in postoperative values in laser-assisted liposuction patients with the change of values in conventional liposuction patients. A paired two-sided Student's $t$-test was used for statistical evaluation. $P<0.005$ was acknowledged to be statistically significant.

Results: Values of platelets were raised both in conventional and in laser-assisted liposuction patients, but this difference was statistically non-significant and levels of platelets were still normal and within the range of blood levels in healthy patients. Values of neutrophils rose by up to $79.49 \% \pm 7.74 \%$ standard deviation (SD) and values of lymphocytes dropped by up to $12.68 \% \pm 5.61 \% \mathrm{SD}$. The before/after variances of conventional tumescent local anesthesia liposuction and variations in laser-assisted liposuction were similar for all measured parameters; they also showed no statistically significant differences between before and after surgery. The mean value of total operation time without laser-assistance was 3 hours 42 minutes ( \pm 57 minutes SD, range 2 hours 50 minutes to 5 hours 10 minutes). Surgeries with laser-assistance were on average 16 minutes shorter with a mean duration of 3 hours 26 minutes $( \pm 45$ minutes SD, range 2 hours 40 minutes to 4 hours 10 minutes). The difference was not statistically significant $(P<0.06)$. The mean value of aspirate volume for liposuctions performed without laser support was $2,618 \mathrm{~mL}$ ( $\pm 633.7 \mathrm{SD}$, range $700 \mathrm{~mL}$ to $3,500 \mathrm{~mL}$ ). Mean aspirate volume for liposuctions with laser assistance was increased by up to $61 \mathrm{~mL}(2,677 \mathrm{~mL} \pm 499.5 \mathrm{SD}$, range $1,800 \mathrm{~mL}$ to $3,500 \mathrm{~mL})$. The difference was not statistically significant $(P<0.71)$.

Conclusion: We conclude that conventional liposuction and laser-assisted liposuction have a similar influence on platelets, lymphocytes, and neutrophils in patients. Moreover, laser-assisted liposuction seems to be less time consuming than conventional liposuction.

Keywords: liposuction, laser, platelets, lymphocytes, neutrophils, lipolysis 


\section{Introduction}

Liposuction is a body shaping surgery which appears to have attained a high standard of surgical safety. ${ }^{1,2}$ However, postoperative blood results are not published very often. ${ }^{3}$ In our previous work we showed stable postoperative hematological values such as erythrocytes, hemoglobin, and hematocrits, after liposuction. ${ }^{4}$ There are no papers reporting on thrombocytes, neutrophils, and lymphocytes after liposuction.

Reactive thrombocytosis after major surgeries has been described several times. ${ }^{5,6}$ Here we wish to examine the influence of liposuction on platelet numbers in patients' blood after conventional and after laser-aided liposuction.

Major surgery is associated with a sustained decline in lymphocyte numbers in the post-surgical period. ${ }^{7,8}$

Lymphocytopenia and neutrophilia are symptoms that accompany major surgeries, injuries, sepsis, and systemic inflammation..$^{7-10}$ The objective of this article is to analyze and interpret values of platelets, lymphocytes, and neutrophils in patients before and after liposuction, a surgery in which an extraordinarily large amount of potent drugs are used. Moreover, the aim is to compare value changes in patients after conventional and laser-assisted liposuction.

\section{Material and methods}

The study was done on routine pre- and post-surgery blood examinations in patients undergoing liposuction.

Only subjects whose health conditions were normal were accepted for surgery. Menstruating women were not accepted for surgery. An evaluation of hematological laboratory parameters (lymphocytes, neutrophils, platelets) was performed on 54 patients ( 26 men, 28 women). The blood values were compared in the non-laser-treated and lasertreated groups.

We used tumescent local anesthesia for treatment of all patients, as described by Klein. ${ }^{1}$ We did a subcutaneous infusion of Klein's tumescence liquid, using about $6,000 \mathrm{~mL}$ with every patient who had liposuction of the abdomen and flanks or those who had liposuction of the inner and outer thighs. We used about 3,000 mL volume of Klein's tumescence liquid with every patient who had liposuction of only a single small body area, for instance, if the surgery was restricted to only the front of the abdomen, flanks, inner thighs, or outer thighs. The first patient group (conventional liposuction) was subjected to standard protocol liposuction involving tumescent local anesthesia (infusion of fluid described by Klein, $0.9 \%$ sodium chloride [ $\mathrm{NaCl}] ; 0.05 \%$ lidocaine; 1:1,000,000 epinephrine). The suction was performed using a vacuum pump with a rated suction power of $0.8-0.9 \mathrm{kPa}$ and a liposuction canula with a diameter of 4-5 mm. ${ }^{1}$ The second group of patients (laserassisted liposuction) was subjected to laser-assisted liposuction using a Nd:YAG laser $1064 \mathrm{~nm}$ with a maximum of $10 \mathrm{~W}$ (Smartlipo-Laser; DEKA M.E.L.A. SRL, Firenze, Italy); the laser was used intraoperatively with a laser-impulse energy range of 800-4,500 Joules, according to the protocol previously described by Goldman ${ }^{11}$ and Kim and Geronemus. ${ }^{12}$ In this surgery, the laser energy is conducted to the subcutaneous tissue through a 300 micron fiber optic device, delivered through a $1 \mathrm{~mm}$ diameter stainless steel microcanula. The product of cellular lysis was removed using negative pressure of $0.8-0.9 \mathrm{kPa}$ with 4-5 mm canulae. All patients received tumescent local anesthesia only. Patient ages ranged from 23- to 56-years-old, and the median age was 35.8 years. The preoperative blood examinations were carried out $7-10$ days prior to surgery. The postoperative blood tests were carried out 24 hours after surgery. The mean operative time was 3 hours and 34 minutes. Patients were discharged within 2 hours after surgery. The postoperative recovery of every patient was normal and without serious complications. The infection rate was 0.0 .

\section{Statistical methods}

A paired two-sided Student's $t$-test was carried out for statistical evaluation. $P<0.005$ was acknowledged to be statistically significant.

\section{Results}

The aspirate volume obtained through the procedure ranged from 700 to $3,500 \mathrm{~mL}$ of fat. The median fat removal was $2,650 \mathrm{~mL}$.

We found that platelet count was higher after surgery than before surgery (Figure 1A). This difference was statistically non-significant. This was the case in both conventional and in laser-assisted treatment $(P<0.019$ and $P<0.032$, respectively). This was emphasized even when the higher, postoperative blood levels of platelets were still normal and within the range of blood levels in healthy patients.

In conventional liposuction patients, the mean preoperative platelet count was $264.07 \times 10^{9} / \mathrm{L} \pm 35.19$ standard deviation $(\mathrm{SD})\left(\right.$ range, $195.0 \times 10^{9} / \mathrm{L}$ to $333.0 \times 10^{9} / \mathrm{L}$ ) in laser-assisted liposuction patients the mean preoperative platelet count was $294.25 \times 10^{9} / \mathrm{L} \pm 57.41 \mathrm{SD}$ (range, $201.0 \times 10^{9} / \mathrm{L}$ to $373.00 \times 10^{9} / \mathrm{L}$ ) (Figure $\left.1 \mathrm{~A}\right)$. Postoperative values increased in conventional liposuction patients to a mean of $289.07 \times 10^{9} / \mathrm{L} \pm 37.2 \mathrm{SD}$ (range, $230.0 \times 10^{9} / \mathrm{L}$ to $332.0 \times 10^{9} / \mathrm{L}$ ) and in laser-assisted liposuction patients to a mean of $317.0 \times 10^{9} / \mathrm{L} \pm 58.62 \mathrm{SD}$ (range, $237.0 \times 10^{9} / \mathrm{L}$ to $435.0 \times 10^{9} / \mathrm{L}$ ) (Figure $\left.1 \mathrm{~A}\right)$. The mean increase in the 
A

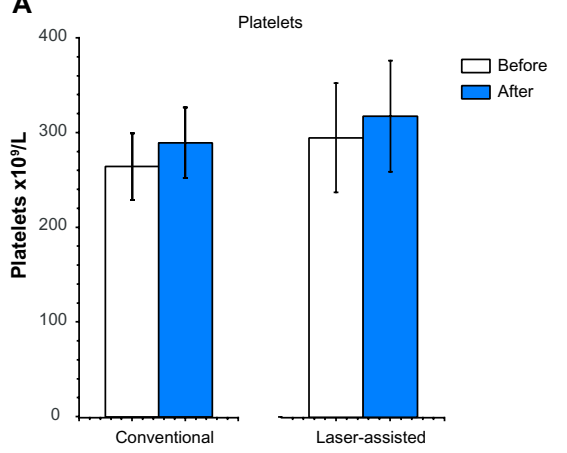

B

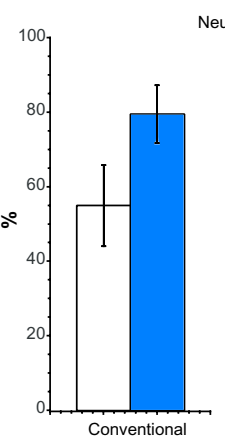

Neutrophils

C

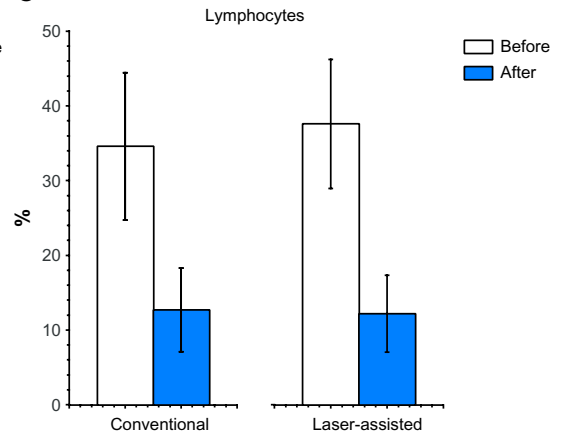

Figure I Preoperative and postoperative values of platelets, neutrophils and lymphocytes in liposuction patients.

Notes: Preoperative and postoperative values of $(\mathbf{A})$ platelets, $(\mathbf{B})$ neutrophils, and $(\mathbf{C})$ lymphocytes in conventional and laser-assisted liposuction-treated patients.

platelet level was $25.0 \times 10^{9} / \mathrm{L} \pm 34.81 \mathrm{SD}$ for conventional liposuction, and $22.75 \times 10^{9} / \mathrm{L} \pm 32.09 \mathrm{SD}$ for laser-assisted liposuction patients (Table 1 ).

We found that the level of neutrophils was higher after surgery than before surgery (Figure 1B.). This difference was statistically significant $(P<0.0005)$. This was the case in both conventional and laser-assisted treatments. Postoperative blood levels of neutrophils were outside the range of blood levels in healthy patients.

In patients treated with conventional liposuction, the mean preoperative level of neutrophils was $54.91 \% \pm 10.89 \%$ SD (range 29.60\%-69.60\%); in contrast, the same values with laser-assisted liposuction were $50.45 \% \pm 10.25 \% \mathrm{SD}$ (range 34.8\%-68.0\%) (Figure 1B).

The postoperative neutrophil level in conventional liposuction patients increased to a mean of $79.49 \% \pm 7.74 \% \mathrm{SD}$ (range 63.8\%-91.6\%). In laser-assisted liposuction patients, values increased up to a mean of $74.91 \% \pm 11.84 \%$ SD (range $51.2 \%-86.6 \%$ ). The mean increase in the neutrophil level was $24.58 \% \pm 12.22 \%$ SD for conventional liposuction, and $24.45 \% \pm 12.4 \%$ SD for laser-assisted liposuction patients (Table 1).

We found that the post-surgery lymphocyte level was lower than prior to the operation (Figure 1C). This difference was statistically significant $(P<0.0005)$. This was the case in both conventional and in laser-assisted treated patients.

Table I Mean difference of blood values before and after surgery in patients of conventional and laser-assisted liposuction

\begin{tabular}{lcc}
\hline Parameter & $\begin{array}{l}\text { Laser-assisted } \\
\text { liposuction patients }\end{array}$ & $\begin{array}{l}\text { Conventional } \\
\text { liposuction patients }\end{array}$ \\
\hline $\begin{array}{l}\text { Platelet count } \\
\left(\times 10^{\circ} / \mathrm{L}\right)\end{array}$ & $-22.75 \pm 32.09$ & $-25.0 \pm 34.8 \mathrm{I}$ \\
Neutrophils $(\%)$ & $-24.45 * \pm 12.4$ & $-24.58^{*} \pm 12.22$ \\
Lymphocytes $(\%)$ & $25.4 I^{*} \pm 6.07$ & $21.9 * \pm 11.54$ \\
\hline
\end{tabular}

Note: $* P<0.005$.
Postoperative blood levels of lymphocytes were outside the range of blood levels in healthy patients.

In conventional liposuction patients the mean lymphocyte level before surgery was $34.6 \% \pm 9.86 \%$ SD (range $20.4 \%-50.2 \%$ ), while in laser-assisted liposuction patients the mean lymphocyte level was $37.6 \% \pm 8.63 \% \mathrm{SD}$ (range $23.5 \%-54.3 \%$ ). The postoperative mean values of lymphocytes in conventional liposuction patients decreased by up to $12.68 \% \pm 5.61 \%$ SD (range 6.7\%-29.2\%), and in laser-aided liposuction patients they decreased to $12.18 \pm 0.16 \mathrm{SD}$ (range $6.9 \%-28.3 \%$ ) (Figure 1C).

The mean decrease of lymphocyte values was $21.91 \% \pm 11.54 \% \mathrm{SD}$ and $25.41 \pm 6.07 \mathrm{SD}$ in conventional and laser-assisted liposuction patients, respectively (Table 1).

The mean value of total operation time of lipectomies performed without laser-support was 3 hours 42 minutes ( \pm 57 minutes $\mathrm{SD}$, range 2 hours 50 minutes to 5 hours 10 minutes). Surgeries with laser-support were on average 16 minutes shorter, with a mean duration of 3 hours 26 minutes ( \pm 45 minutes SD, range 2 hours 40 minutes to 4 hours 10 minutes) (Table 2). The difference was not statistically significant $(P<0.06)$.

The mean value of aspirate volume for liposuctions performed without laser support was $2,618 \mathrm{~mL}( \pm 633.7 \mathrm{SD}$, range $700 \mathrm{~mL}$ to $3,500 \mathrm{~mL}$ ). Mean aspirate volume for liposuctions with laser increased by up to $61 \mathrm{~mL}$, with $2,677 \mathrm{~mL}$ ( $\pm 499.5 \mathrm{SD}$, range $1,800 \mathrm{~mL}$ to $3,500 \mathrm{~mL}$ ) (Table 3 ). The difference was not statistically significant. $(P<0.71)$.

Table 2 Mean total operation time of laser-assisted and conventional liposuction

\begin{tabular}{lll}
\hline Parameter & $\begin{array}{l}\text { Laser-assisted } \\
\text { liposuction } \\
\text { patients }( \pm S D)\end{array}$ & $\begin{array}{l}\text { Conventional } \\
\text { liposuction } \\
\text { patients }( \pm S D)\end{array}$ \\
\hline Mean total operation & 3 hours 42 minutes & 3 hours 26 minutes \\
time (hours) & $( \pm 0.57$ minutes SD) & $( \pm 0.45$ minutes SD) \\
\hline
\end{tabular}

Abbreviation: SD, standard deviation. 


\section{Discussion}

In our previous work we showed stable postoperative hematological values like erythrocytes, hemoglobin, and hematocrit after the liposuction. ${ }^{4}$ In this study we examined platelet, neutrophil, and lymphocyte counts in patients' blood after liposuction.

Liposuction with tumescent local anesthesia is a very specific procedure that is not comparable with other major surgeries - liposuction is a surgery in which an extraordinarily large amount of potent drugs are used. Therefore we cannot consider the influence of the liposuction as a major surgery alone, but we should rather also take into account the influence of steroids (methylprednisolone), adrenaline, and lidocaine. The final blood examination results obtained 24 hours after the surgery reflect the effects of the interactions of all the components mentioned above. Each component alone has a strong enough effect on the examined parameter. Why this composition results in the counts reported requires some brief annotations.

In this study we determined that liposuction (conventional and laser-assisted) does not have an impact on platelet levels within 24 hours after the surgery. Major surgery results in a tendency to increase the reactive platelet count in patients' blood. ${ }^{5}$ The influence of steroids on patients is difficult to interpret because they have rather incoherent double-sided effects on platelets. ${ }^{13,14}$ Adrenaline enhances the number of platelets in human blood ${ }^{15,16}$ whereas another component of Klein's solution - lidocaine - decreases the number of platelets ${ }^{17}$ in the initial few days after surgery. The data found in pertinent literature allows one to conclude that the interactive output of such opposite actions may be neutral as far as the platelet count is concerned. Therefore, the surgery itself may have the greatest impact on platelet count in the blood. Under these conditions, an unchanged platelet count suggests that both conventional and laser-assisted liposuction are rather mildly invasive procedures.

Here we found that liposuction evokes neutrophilia in peripheral blood 24 hours after the procedure; major surgery also usually results in neutrophilia. ${ }^{9}{ }^{10}$ Therefore, our results are compatible with expectations. Epinephrine increases the

Table 3 Mean aspirate volume of laser-assisted and conventional liposuction

\begin{tabular}{lll}
\hline Parameter & $\begin{array}{l}\text { Laser-assisted } \\
\text { liposuction } \\
\text { patients }( \pm S D)\end{array}$ & $\begin{array}{l}\text { Conventional } \\
\text { liposuction } \\
\text { patients }( \pm S D)\end{array}$ \\
\hline $\begin{array}{l}\text { Mean aspirate } \\
\text { volume }(\mathrm{mL})\end{array}$ & $2,677 \mathrm{~mL}( \pm 499.5 \mathrm{SD})$ & $2,618 \mathrm{~mL}( \pm 633.7 \mathrm{SD})$ \\
\hline Abbreviation: SD, standard deviation. &
\end{tabular}

number of neutrophils, ${ }^{24}$ and thus potentiates the effect of major surgery; however, other compounds of Klein's solution act contrarily to epinephrine. Steroids ${ }^{25}$ as well as lidocaine reduce the number of neutrophils in human blood. ${ }^{26,27} \mathrm{In}$ the case of our patients, both steroids and lidocaine used in combination were not able to reduce the neutrophil count in peripheral blood. We can surmise that the rise of neutrophils in blood through a major surgery and through epinephrine prevail in changing the neutrophil level.

In this case we found that liposuction results in strong lymphopenia within 24 hours after the procedure. Every major surgery results in lymphopenia; ${ }^{18,19}$ therefore, our results are compatible with expectations. Moreover, lidocaine seems to induce lymphopenia as well. ${ }^{20}$ Additionally prednisone, a steroid we administer to patients as preoperative medication, should decrease the peripheral blood lymphocytes..$^{23}$ Under these circumstances, it is possible to expect an even stronger depletion in the number of lymphocytes. However, another component of Klein's solution, epinephrine, does not behave this way ${ }^{21,22}$ and instead raises lymphocyte levels. This combined action of epinephrine is not strong enough to equalize the inhibiting effect of surgery, lidocaine, and steroid. However, this complex interaction of drugs probably supports the number of lymphocytes in blood and makes patients' immunological status after the surgery less urgent.

In this study we compared the blood values of two patient groups post-procedure: one group that had received laser-assisted liposuction treatment, and the other that had received conventional (non-laser-assisted) treatment. Both groups showed that the impact on platelets, lymphocytes, and neutrophils was virtually identical. Moreover, we compared the pre- and post-value difference of conventional tumescent local anesthesia liposuction versus the pre- and post-value difference of laser-assisted liposuction. The results were similar for all measured parameters and showed no statistically significant difference.

We noted that total operation time was 16 minutes shorter (mean value) when laser-assisted surgery was done. However, this difference was not statistically significant. Nevertheless, we must take into account that such an operation consists of one additional treatment step (the laser procedure) which requires 20 minutes. Under these circumstances the total time of surgery was 16 minutes shorter. This indicates that fat removal time taken alone was effectively 36 minutes shorter. Moreover, according to subjective experience, body regions with more resistant fat, eg, the upper abdomen, are definitely easier to treat with laser assistance. 
The increase of mean aspirate volume under laser assistance versus conventional liposuction was rather small $(61 \mathrm{~mL})$. Here it should be taken into account that patients have their individual needs, which are precisely set. These needs should be adhered to all circumstances. Whether the conditions are simpler or more challenging, the demanded patient shape (expressed as aspirate volume) must be reached. With this in mind, even enhancing the aspirate volume seems to be undesirable because it can lead to over-correction. Therefore, nearly unchanged aspirate volume speaks to the positive nature of the standardized treatment and not to ineffectiveness of laser-assisted liposuction.

\section{Conclusion}

We conclude that conventional liposuction and laser-assisted liposuction have similar influences on platelets, lymphocytes, and neutrophils. Moreover, laser-assisted liposuction seems to be less time-consuming than conventional liposuction. Our work is the first study that documents the platelet counts during postoperative care after laser-assisted liposuction. This emphasizes that every patient has normal blood platelet counts after surgery, no matter the type of liposuction. This work is also the first that documents the neutrophil and lymphocyte counts after the liposuction.

\section{Disclosure}

The authors report no conflicts of interest in this work. This work was supported in part by grants from Medical University of Białystok No 123-30849 F.

\section{References}

1. Klein JA. The Tumescent technique for liposuction surgery. Am J Cosmet Surg. 1987;4:263-267.

2. Hanke CW, Bernstein G, Bullock S. Safety of tumescent liposuction in 15,336 patients. National survey results. Dermatol Surg. 1995;21(5): 459-462.

3. Karmo FR, Milan MF, Silbergleit A. Blood loss in major liposuction procedures: a comparison study using suction-assisted versus ultrasonically assisted lipoplasty. Plast Reconstr Surg. 2001;108(1): 241-247; discussion 248-249.

4. Peterson AF, Przylipiak J, Peterson M. Influence of laser-supported liposuction on hemoglobin, hematocrit, and erythrocyte values in patient's blood. Eur J Plast Surg. 2009;32(6):283-286.

5. Schafer AI. Thrombocytosis. N Engl J Med. 2004;350(12):1211-1219.

6. Griesshammer M, Bangerter M, Sauer T, Wennauer R, Bergmann L, Heimpel H. Aetiology and clinical significance of thrombocytosis: analysis of 732 patients with an elevated platelet count. J Intern Med. 1999;245(3):295-300.
7. Sugimoto M, Shimaoka M, Hosotsubo K, et al. Up-regulation of Fas ligand (FasL) mRNA expression in peripheral blood mononuclear cells (PBMC) after major surgery. Clin Exp Immunol. 1998;112(1): $120-125$.

8. Tayama E, Hayashida N, Oda T, et al. Recovery from lymphocytopenia following extracorporeal circulation: simple indicator to assess surgical stress. Artif Organs. 1999;23(8):736-740.

9. Carey PD, Wakefield CH, Thayeb A, Monson JR, Darzi A, Guillou PJ. Effects of minimally invasive surgery on hypochlorous acid production by neutrophils. Br J Surg. 1994;81(4):557-560.

10. Kobayashi E, Yamauchi H. Interleukin-6 and a delay of neutrophil apoptosis after major surgery. Arch Surg. 1997;132(2):209-210.

11. Goldman A. Submental Nd:Yag laser-assisted liposuction. Lasers Surg Med. 2006;38(3):181-184.

12. Kim KH, Geronemus RG. Laser lipolysis using a novel $1,064 \mathrm{~nm}$ Nd:YAG laser. Dermatol Surg. 2006;32(2):241-248; discussion 247.

13. Suares CR, Rademaker D, Hasson A, Mangogna I. High-dose steroids in childhood acute idiopathic thrombocytopenia purpura. Am J Ped Hematol Oncol. 1986;8(2):111-115.

14. Hutschinson RM, Davis P, Jayson MI. Thrombocytosis in rheumatoid arthritis. Ann Rheum Dis. 1976;35(2):138-142.

15. Bierman HR, Kelly KH, Cordes FL, Byron RL, Polhemus JA, Rappoport S. The release of leukocytes and platelets from the pulmonary circulation by epinephrine. Blood. 1952;7(7):683-692.

16. Lande K, Kjeldsen SE, Os I, et al. Increased platelet and vascular smooth muscle reactivity to low-dose adrenaline infusion in mild essential hypertension. J Hypertens. 1988;6(3):219-225.

17. Waldman FM, Koblin DD, Lampe GH, Wauk LZ, Eger EI. Hematologic effects of Nitrous oxide in surgical patients. Anesth Analg. 1990;71(6):618-624.

18. Toft P, Svendsen P, Tønnesen E, Rasmussen JW, Christensen NJ. Redistribution of lymphocytes after major surgical stress. Acta Anaesthesiol Scand. 1993;37(3):245-249.

19. Hensler T, Hecker H, Heeg K, et al. Distinct mechanisms of immunosuppression as a consequence of major surgery. Infect Immun. 1997;65(6):2283-2291.

20. Moore TC, Khan F. Lymphocyte traffic effects of systemic and local lidocaine in sheep. J Surg Res. 1986;41(3):279-285.

21. Toft P, Tønnesen E, Svendsen P, Rasmussen JW, Christensen NJ. The redistribution of lymphocytes during adrenaline infusion. An in vivo study with radiolabelled cells. APMIS. 1992;100(7):593-597.

22. Erikson B, Hedfors E. The effect of adrenaline, insulin, and hydrocortisone on human periferial blood lymphocytes studied by cell surface markers. Scand J Hematology. 1977;18(1):121-128.

23. Toft P, TØnnesen E, Svendsen P, Rasmussen JW. Redistribution of lymphocytes after cortisol administration. APMIS. 1992;100(2):154-158.

24. Samuels AJ. Primary and secondary leucocyte changes following the intramuscular injection of epinephrine hydrochloride. J Clin Invest. 1951;30(9):941-947.

25. O'Malley BW. Mechanism of action of steroid hormones. $N$ Engl J Med. 1971;284(7):370-377.

26. Ohsaka A, Saionji K, Sato N, Igari J. Local anesthetic lidocaine inhibits the effect of granulocyte colony-stimulating factor on human neutrophil functions. Exp Hematol. 1994;22(5):460-466.

27. Benlier E, Eskiocak S, Puyan FO, et al. Effect of lidocaine on reducing injury in a rat electrical burn model. Ann Plast Surg. 2012;69(2): $152-156$. 


\section{Publish your work in this journal}

Drug Design, Development and Therapy is an international, peerreviewed open-access journal that spans the spectrum of drug design and development through to clinical applications. Clinical outcomes, patient safety, and programs for the development and effective, safe, and sustained use of medicines are a feature of the journal, which

has also been accepted for indexing on PubMed Central. The manuscript management system is completely online and includes a very quick and fair peer-review system, which is all easy to use. Visit http://www.dovepress.com/testimonials.php to read real quotes from published authors.

Submit your manuscript here: http://www.dovepress.com/drug-design-development-and-therapy-journal 